\title{
Clinical Profile of Patients with Carcinoma Cervix in a Tertiary Level Hospital
}

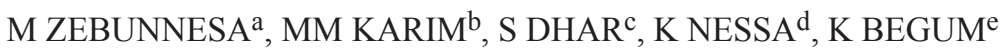

\begin{abstract}
Summary:
Cervical carcinoma is a preventable condition and over $95 \%$ of patients with early carcinoma cervix can be cured. But still women dying from malignant disease of all kinds the cervix is the common organ primarily involved. The study was conducted to find out the predisposing factors of carcinoma cervix in our population and to scrutinize the patients in early stages, so that measures can be taken to prevent it. After approval of ethical committee and informed written consent fifty patients from Dhaka Medical College hospital were included in this study from January 2003 to December 2003. Among the 50 patients 36 were between 31 to 50 years, 42 patients present with blood stained per
\end{abstract}

\section{Introduction:}

The cervix is the commonest site for female genital cancer. ${ }^{1}$ Cervical cancer is the second most common cancer among women worldwide after breast cancer. ${ }^{2}$ Globally it was responsible for 275000 deaths in $2008 .^{3}$ Nearly $83 \%$ of these deaths occurred in developing countries where it is the $10^{\text {th }}$ most common cancer. ${ }^{4}$ Among women, it is the leading cause of cancer mortality, accounting for $26 \%$ of all cancer deaths. ${ }^{5}$ In the developing countries carcinoma cervix is the most common malignancy in the female and a major public health problem. ${ }^{6}$ The estimated new cancer cervix cases per year is 500.000 of which $79 \%$ occur in the developing countries like us. ${ }^{7}$ Due to availability of routine screening

a. Dr. Moshammat Zebunnesa, Junior Consultant (Gynae), Upazila Health Complex, Manikchari, Khagrachari.

b. Dr. Mohammad Masud Karim, Assistant Professor (Surgery), Chittagong Medical College.

c. Dr. Satyajit Dhar, Assistant Professor (Anesthesia), Chittagong Medical College

d. Dr. Kamrun Nessa, Senior Consultant (Gynae \& Obs.), Chittagong Medical College Hospital.

e. Prof. Kohinoor Begum, Professor (Gynae \& Obs.), Bangladesh Medical College.

Address of Correspondence: Moshammat Zebunnesa, Junior Consultant (Gynae), Upazila Health Complex, Manikchari, Khagrachari, Mobile : 01819383580,Email : mzebunnesa@gmail.com Received: 11 Nov. 2015

Accepted: 15 June 2017 vaginal discharge and 40 present with post-coital bleeding. Regarding identifiable risk factors early age of 1 st intercourse was most common followed by multiparity. Ninety four percent of patients had squamous cell carcinoma and reminder were adenocarcinoma. Incidence of carcinoma cervix can be decreased by health education with special attention to risk factors and morbidity and mortality can be reduced by detection of cases in early stage when it is still curable.

Key words : Carcinoma cervix, Early detection, Predisposing factors.

(J Bangladesh Coll Phys Surg 2017; 35: 110-114)

for detecting carcinoma in situ and availability of proper management, the incidence of invasive carcinoma has greatly reduced. ${ }^{6}$ According to cancer registry report, In Bangladesh, carcinoma cervix is the second most common cancer among female which is $21.5 \%{ }^{8}$

The cause of carcinoma cervix is not known but certain predisposing factors are recognized such as early marriage, low socioeconomic condition, multiparity, early age of first intercourse, multiple sexual partner, high risk male partner, sexually transmitted diseases, immunosuppressant, oral contraceptive pill. HPV type $16 \& 18$ has stronger association with cervical carcinoma. ${ }^{1}$ Western countries have seen a dramatic fall in the occurrence of cervical cancer due to widespread conduction of pap smear.

In very early stage, invasive cervical carcinoma causes no symptoms \& is only discovered accidentally or as a result of routine search. Abnormal vaginal bleeding or discharge are the most common symptoms of invasive carcinoma. First episode of bleeding com---monly follows coitus, straining at stool or any circumstance which exposes the cervix. Bleeding may be slight in the beginning and become alarmingly heavy later. The discharge is creamy or white at first but subsequently dirty brown and of a particular offensive odor. In 
advanced stage, patient complains of pelvic pain, frequency of micturation, dysuria, incontinence, rectal pain, low backache, oedema of the leg, weight loss, anorexia. Western countries have seen a dramatic fall in the occurrence of cervical cancer due to widespread conduction of pap smear.

In early stage cervical carcinoma may appear normal, eroded or chronically infected. Infiltrative carcinoma causes enlargement, irregularity and firm consistency of the cervix which eventually involves the adjacent parametrium. The cardinal signs are hardness, friability, fixation \& bleeds on touch. When the patient comes with symptoms, diagnosis is usually done by cervical biopsy. About $95 \%$ of cervical carcinoma is squamous cell in type.

Cervical carcinoma is a preventable condition. Over $95 \%$ of patient with early carcinoma cervix can be cured. ${ }^{6}$ Treatment of the carcinoma cervix depends upon the stage. Surgery, Radiotherapy and Chemotherapy can be offered as treatment option.

\section{Aims and Objectives:}

The purpose of this study was to determine the sociodemographic characteristics of cervical cancer patients attending tertiary level hospital of Bangladesh as well as to identify the population groups that are more susceptible to develop carcinoma of the cervix so that measures can be taken to prevent the disease by identifying the risk factors.

\section{Methods:}

After approval of institutional ethical committee, this prospective study was conducted in Dhaka Medical College Hospital by taking 50 randomly selected patients of carcinoma cervix over a period of one year (January 2003 to December 2003).

After taking informed written consent, these patients were selected from Gynae out patients department, Radiotherapy department and Gynae ward. After taking careful history, indication clinical examination, cervical biopsy was taken from that patient who attended at Gynae OPD and admitted in inpatient department for confirmation. After confirmation staging were done. Intravenous urography, X-ray chest P/ A view were done in all cases. Then cases were selected for treatment with surgery, radiotherapy and chemotherapy as suitable for the patients.

The results were calculated and interpreted through appropriate statistical analysis with the help of a statistician and presented with table, pie chart.

\section{Results:}

Sixty-two patients of carcinoma cervix were included in the series. But 12 patients were excluded from the study due to absence from regular follow up. Most of the patients (46\%) were between 31-40 years age group. Among the patients, $88 \%$ were housewives. All patients were married and $56 \%$ of patients were from lower socio-economic group.

\section{Table-I}

\begin{tabular}{|c|c|c|}
\hline \multicolumn{3}{|c|}{ Demography of Study Population $(n=50)$} \\
\hline Parameters & No & $\%$ \\
\hline \multicolumn{3}{|l|}{ Age Group: } \\
\hline $21-30$ & 5 & 10 \\
\hline $31-40$ & 23 & 46 \\
\hline $41-50$ & 13 & 26 \\
\hline $51-60$ & 7 & 14 \\
\hline $61-70$ & 2 & 4 \\
\hline \multicolumn{3}{|l|}{ Occupation: } \\
\hline House wife & 44 & 88 \\
\hline Service holder & 6 & 12 \\
\hline \multicolumn{3}{|l|}{ Marital Status: } \\
\hline Married & 45 & 90 \\
\hline Unmarried & 0 & 0 \\
\hline Widow & 5 & 10 \\
\hline \multicolumn{3}{|c|}{ Socioeconomic Status: } \\
\hline Lower & 28 & 56 \\
\hline Middle & 14 & 28 \\
\hline High & 8 & 16 \\
\hline
\end{tabular}

\section{Table-II}

Mode of presentations of cases of carcinoma cervix.

\begin{tabular}{lcc} 
Presentation & $\begin{array}{c}\text { Number of } \\
\text { cases }\end{array}$ & Percentage \\
\hline Blood stained P/V discharge & 42 & 84 \\
Post coital bleeding & 40 & 80 \\
Foul smelling P/V discharge & 28 & 56 \\
Menorrhagia & 13 & 26 \\
Metrorrhagia & 11 & 22 \\
Spotting & 8 & 16 \\
Backache & 6 & 12 \\
Vulval oedema & 6 & 12 \\
Lower abdominal pain & 5 & 10 \\
Leg oedema & 3 & 6 \\
Frequency of micturation & 3 & 6 \\
Haematuria & 2 & 4 \\
\hline
\end{tabular}


Most common presentation was blood stained pervaginal bleeding ( $84 \%$ ) followed by post coital bleeding $(80 \%)$.

\section{Table-III}

\section{Risk factors in the study population}

\begin{tabular}{lcc} 
Risk factors & $\begin{array}{c}\text { Number of } \\
\text { cases }\end{array}$ & Percentage \\
\hline Early age of first intercourse & 40 & 80 \\
Multiparity (More than 4) & 37 & 74 \\
Early marriage & 36 & 72 \\
Low socio-economic group & 28 & 56 \\
High risk male partner & 12 & 24 \\
Multiple sex partner & 9 & 18 \\
Oral contraceptive pill & 8 & 16 \\
Early menerchae & 7 & 14 \\
Late menopause & 3 & 6 \\
Smoking & 3 & 6 \\
Sexually transmitted disease & 3 & 6 \\
\hline
\end{tabular}

Regarding identifiable risk factors early age of $1^{\text {st }}$ intercourse was most common $(80 \%)$ followed by multiparity (74\%) and early marriage (72\%). 14\% patients had early menerchae and $6 \%$ had late menopause.

\section{Table-IV}

\section{Status of general physical examination}

\begin{tabular}{lcc}
$\begin{array}{l}\text { General physical } \\
\text { examination }\end{array}$ & $\begin{array}{c}\text { Number of } \\
\text { cases }\end{array}$ & Percentage \\
\hline Anemia & 49 & 98 \\
Weight loss & 36 & 72 \\
\hline
\end{tabular}

Ninety eight percent of patients were clinically anaemic with weight loss in $72 \%$.

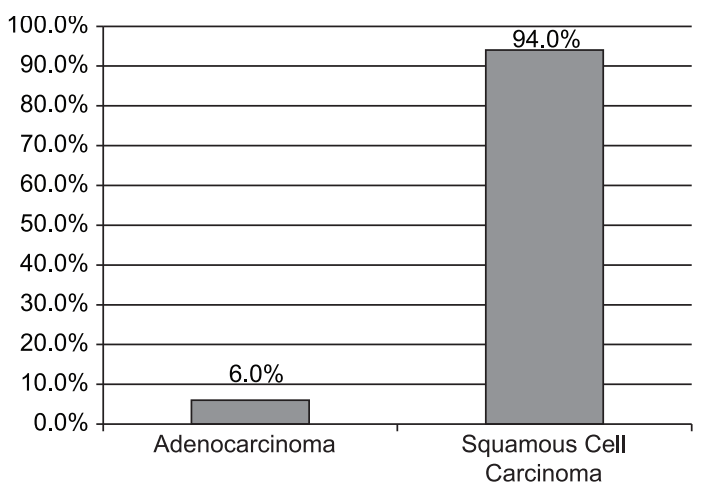

Fig.-1: Histological types of carcinoma cervix
94\% (ninety-four percent) patients had squamouis cell carcinoma and the remainder $6 \%$ (six percent) has adenocarcinoma.

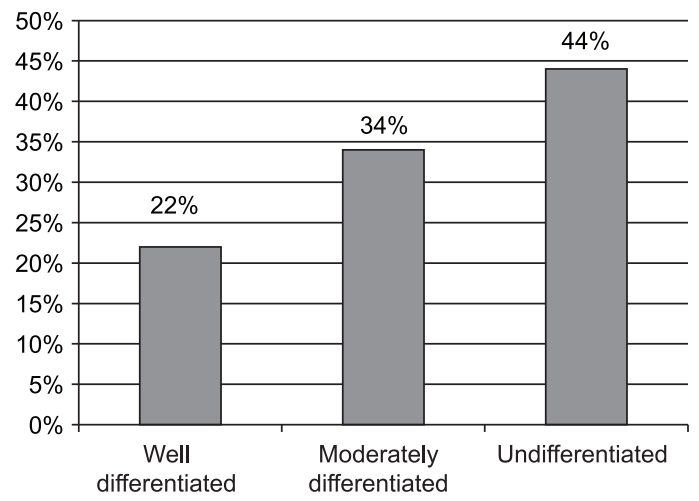

Fig.-2: Histological grading of cervical carcinoma

Most of them were in advanced stage. Two patients had liver and lung metastasis and one had metastasis in brain.

\section{Discussion:}

The primary objectives of this study were to analyze the clinical presentations. In this study most common presentation of ca cervix was blood stained per-vaginal discharge, which is about $84 \%$. It was about $70 \%$ in a study done by Banu L. $\mathrm{A}^{9}$ and $61 \%$ in the study by Fauzia. ${ }^{10}$ Post coital bleeding were also noted in $80 \%$ of patients in this series which was about $30 \%$ in the study conducted by Banu L. A. ${ }^{9}$ Besides these. $56 \%$ patients presented with foul smelling per-vaginal discharge, 26\% with menorrhagia, In Banu L. A series foul smelling per-vaginal discharge were presenting $40 \%$ and menorrhagia were $10 \% .{ }^{9}$

Among the 50 patients studied in this series early age of $1^{\text {st }}$ intercourse was the most common identified risk factors. $80 \%$ patients had $11^{\text {st }}$ intercourse before 15 years. In Banu L. ${ }^{9}$ A series $60 \%$ were before 15 years and $40 \%$ were between 15 to 20 years. Thirty six patients (72\%) had their marriage before 15 years. Twenty-eight patients $(56 \%)$ came from low socio-economic class. $28 \%$ from middle class and $16 \%$ from higher class. It was $30 \%$ and $60 \%$ and $10 \%$ respectively in Banu L. A series. ${ }^{9}$ High prevalence of carcinoma cervix in lower socio-economic group may be due to less availability of medical facilities to poor patients as well as their ignorance and illiteracy about health. Low socio- 
economic condition and poor personal hygiene were also identified as the risk factor by Fauzia. ${ }^{10}$

High risk male partner like rickshaw puller, hawkers etc. were recorded in $24 \%$ of patients. $18 \%$ patients had multiple sexual partner which is also an important risk factor.

Exposure to HPV and HIV were not studied in this series due to lack of facilities. But there is increased risk in patients infected with HPV and HIV. ${ }^{11}$ There is a higher rate of persistent HPV infections in HIV positive patients, especially with oncogenic virus subtypes. Persistence of high-risk virus is necessary for the development of dysplastic lesion; therefore, there is a higher incidence of cervical intra-epithelial neoplasias (CIN) and cervical cancers in HIV positive patients. ${ }^{11}$

Age ranged between 25 to 62 years with a mean age of $37.5 \pm 8.2$ years. Forty six percent patients were between $31-40$ years age group and $26 \%$ in between $41-50$ years age group. In a series by Banu L.A showed $50 \%$ patient were between $20-40$ years and $40 \%$ were between 41 5 - years. ${ }^{9}$ It was $31.5 \%$ between $41-50$ years age group and $21.9 \%$ in $41-50$ years age group in BENEDET's series. ${ }^{12}$ In the series reported by Roy. N.N about $65 \%$ patients were between 31-40 years. ${ }^{13}$

In the series $98 \%$ patients were anemic, which co-relates with Banu L. A series. Significant weight loss were noted in $72 \%$ patients which is as usual with other malignancies. Owing to liver metastasis $4 \%$ patients had jaundice. One patient had brain metastasis, which is a rare observation in cervical carcinoma.

Fifty percent of patients had vaginal involvement which is about $40 \%$ in Banu L. A series. ${ }^{9}$ Regarding characteristics of growth $40 \%$ were ulcerative, $14 \%$ were exophytic and endophytic were $6 \%$. It was $40 \%$, $38 \%$ and $18 \%$ respectively in the series by Fauzia. ${ }^{10}$ Ulcerative lesion was 50\% in Banu L. A series. ${ }^{9}$ During per vaginal examination bleeding were noted in $84 \%$ patients and foul smelling discharge in $56 \%$ patients, which were $100 \%$ and $50 \%$ respectively in Banu L. A series. ${ }^{9} 76 \%$ patients had friable cervical growth with hard consistency in $24 \%$ of patients.

Cervical biopsy of the patients showed $94 \%$ patients had squamous cell carcinoma of different grades and
$6 \%$ had adenocarcinoma. Squamous cell carcinoma was $91 \%$ in the study conducted by Fauzia. ${ }^{10}$ In Banu L. A series of 10 patients $100 \%$ were squamous cell carcinoma. ${ }^{9}$ But in CCABC and Vancouver series of 241 cases, 185 were squamous cell carcinoma, 28 were adenocarcinoma and 13 were mixed adenosquamous carcinoma. ${ }^{14}$ In this series all were invasive carcinoma. None of my patients in this series were micro invasive or occult carcinoma, probably due to unavailability of routine screening program.

\section{Conclusion:}

Our study showed that high proportion of cervical cancer patients at tertiary level hospital are late presenters. Among the study population major risk factors for cervical cancer includes, early age at first intercourse, multiple sexual partners, low socio-economic status. Well organized and applied public health education particularly among the low socio-economic group with special attention to risk factors like early marriage, sexual behavior, genital hygiene etc. and mass screening programs can substantially reduce the morbidity and mortality from cervical cancer. Vaccination against HPV for girls of nine years and above can be included in national immunization program.

\section{References:}

1. Jeffcoate N. Tumours of the cervix uteri. In: Neerja Bhatla, editor. Jeffcoate's Principles of Gynaecology, $5^{\text {th }}$ International edn, Arnold, 2001 : 447-465.

2. Senapathy JG, Umadevi P, Kannika PS. The present scenario of cervical cancer control and HPV epidemiology in India: An outline. Asian Pac J Cancer Prev. 2011;12:1107-15.

3. Ferlay J, Shin HR, Bray F, Forman D, Mathers C, Parkin DM. Estimates of worldwide burden of cancer in 2008: GLOBOCAN 2008. Int JCancer. 2010; 127:2893-917.

4. Shanta V, Krishnamurthi S, Gajalakshmi CK, Swaminathan R, Ravichandran K. Epidemiology of cancer of the cervix: Global and national perspective. J Indian Med Assoc. 2000;98:49-52.

5. World Health Organization. GLOBACAN 2002 Database, International Agency for Research on Cancer, World Health Organization. 2002.

6. Alan H. decherney, MD, Lauren Nathan. Premalignant and malignant disorders of the uterine cervix. In : Current Obstetric and Gynecologic Diagnosis and Treatment, $9^{\text {th }}$ edn, USA, 2003: 894-914

7. Altekruse SF, Lacey JV Jr, Briton LA, Gravitt PE, Silverberg $\mathrm{SG}$, Barnes WA Jr, et al. Comparison of human papillomavirus 
genotypes, sexual and reproductive risk factors of cervical adenocarcinoma and squamous cell carcinoma: Northeastern United States. Division of cancer Epidemiology and Genetics, National Cancer Institute, Bethesda, Md 20892, USA.

8. Cancer Registry Report National Institute of Cancer Research \& Hospital,2005-7. December, 2009, MOHFW, GOB, NICRH $\&$ WHO.

9. Banu L. A. Surgical Treatment of Carcinoma Cervix (dissertation) Bangladesh; BCPS, 1984.

10. Fauzia, K.J. Maula. Presentation of Invasive cervical cancer. J Bangladesh colls phys surg 2002; 20:115-119.
11. Pautier p, Morice P, de Crevoisier R. HIV and uterine cervical cancer. Oncolague medical, Comite de gynecologic, Institute Gustave-Roussy, 39 Camille-Ddemoulins, 94805 Villejuif.

12. BENEDIT's 30 years study of radical hysterectomy in cancer cervix, Cancer control Agency of British Columbia(CCABC) and Vancouver General Hospital.

13. Roy chowdhury N N. Epidemiological trends in incidence of cancer of the cervix. J Obst. \& Gynae. India 1978(28); $1025-9$

14. Cancer Control Agency of British Columbia(CCABC) and Vancouver General Hospital. 